\title{
Dental microwear reveals mammal-like chewing in the neoceratopsian dinosaur Leptoceratops gracilis
}

Frank J Varriale

Extensive oral processing of food through dental occlusion and orbital mandibular movement is often cited as a uniquely mammalian trait that contributed to their evolutionary success. Save for mandibular translation, these adaptations are not seen in extant archosaurs or lepidosaurs. In contrast, some ornithischian dinosaurs show evidence of precise dental occlusion, habitual intraoral trituration and complex jaw motion. To date, however, a robust understanding of the diversity of jaw mechanics within non-avian dinosaurs, and its comparison with other vertebrates, remains unrealized. Large dental batteries, well developed dental wear facets, and robust jaws suggests that neoceratopsian (horned) dinosaurs were capable chewers. But, biomechanical analyses have assumed a relatively simple, scissor-like (orthal) jaw mechanism for these animals. New analyses of dental microwear, presented here, show curvilinear striations on the teeth of Leptoceratops. These features indicate a rostral to caudal orbital motion of the mandible during chewing. A rostrocaudal mandibular orbit is seen in multituberculates, haramiyid allotherians, and some rodents, and its identification in Leptoceratops gracilis is the first evidence of complex, mammal-like chewing in a ceratopsian dinosaur. The term circumpalinal is here proposed to distinguish this new style of chewing from other models of ceratopsian mastication that also involve a palinal component. This previously unrecognized complexity in dinosaurian jaw mechanics indicates that some neoceratopsian dinosaurs achieved a mammalian level of masticatory efficiency through novel adaptive solutions. 


\section{Dental microwear reveals mammal-like chewing in the 2 neoceratopsian dinosaur Leptoceratops gracilis}

$3 \quad$ Frank J. Varriale ${ }^{1}$

$4 \quad{ }^{1}$ Department of Biology, King's College, Wilkes-Barre, Pennsylvania, United States.

6 Corresponding Author:

$7 \quad$ Frank J. Varriale ${ }^{1}$

8113 North River Street, Wilkes-Barre, Pennsylvania 18711, United States.

9 Email address: frankvarriale@kings.edu. 


\section{Abstract}

13 Extensive oral processing of food through dental occlusion and orbital mandibular movement is

14 often cited as a uniquely mammalian trait that contributed to their evolutionary success. Save for

15 mandibular translation, these adaptations are not seen in extant archosaurs or lepidosaurs. In

16 contrast, some ornithischian dinosaurs show evidence of precise dental occlusion, habitual

17 intraoral trituration and complex jaw motion. To date, however, a robust understanding of the

18 diversity of jaw mechanics within non-avian dinosaurs, and its comparison with other

19 vertebrates, remains unrealized. Large dental batteries, well developed dental wear facets, and

20 robust jaws suggests that neoceratopsian (horned) dinosaurs were capable chewers. But,

21 biomechanical analyses have assumed a relatively simple, scissor-like (orthal) jaw mechanism

22 for these animals. New analyses of dental microwear, presented here, show curvilinear striations 23 on the teeth of Leptoceratops. These features indicate a rostral to caudal orbital motion of the

24 mandible during chewing. A rostrocaudal mandibular orbit is seen in multituberculates,

25 haramiyid allotherians, and some rodents, and its identification in Leptoceratops gracilis is the

26 first evidence of complex, mammal-like chewing in a ceratopsian dinosaur. The term

27 circumpalinal is here proposed to distinguish this new style of chewing from other models of

28 ceratopsian mastication that also involve a palinal component. This previously unrecognized

29 complexity in dinosaurian jaw mechanics indicates that some neoceratopsian dinosaurs achieved 30 a mammalian level of masticatory efficiency through novel adaptive solutions.

\section{Introduction}

33 Mastication, or chewing, is the process by which food items are broken down between precisely

34 occluding teeth via repeated mandibular adduction (Hiiemae, 2000). Often assumed as an 
35 exclusively mammalian feature, the process of mastication increases the surface area of ingested

36 food for subsequent enzymatic action in the digestive system, allowing more efficient energy

37 extraction. However, mounting evidence indicates that the distribution of chewing is more

38 widespread in non-mammalian synapsids (Crompton \& Hotton, 1967; Crompton, 1972;

39 Crompton \& Attridge, 1986; King, Oelofsen \& Rubidge, 1989; King, 1990, 1996; Cox, 1998;

40 Angielczyk, 2004) and sauropsid amniotes than previously thought (Weishampel, 1984; Norman

41 \& Weishampel, 1985; Rybczynski \& Vickaryous, 2001; Ösi \& Weishampel, 2009; O’Connor et

42 al., 2010). Among non-avian dinosaurs, mastication is well supported in hadrosaurid

43 ornithopods. Hadrosaurs possess numerous cranio-dental specializations for mastication,

44 including a jaw joint depressed below the dental arcade, an elongated coronoid process, and most

45 strikingly a dental battery consisting of many closely packed teeth with dentine of differing

46 hardness (Ostrom, 1961; Weishampel, 1984; Norman \& Weishampel, 1985; Williams, Barrett \&

47 Purnell, 2009; Erickson et al., 2012; Cuthbertson et al., 2012). Many neoceratopsians exhibit

48 similar adaptations, providing support for an identical level of masticatory sophistication

49 (Ostrom, 1964, 1966; Tanoue et al., 2009; Erickson et al., 2015). Because neoceratopsian skulls

50 lack intracranial joints with large gaps (Holliday \& Witmer, 2008), and have a simple hinge-like

51 jaw mechanism, biomechanical analyses of their chewing infer an unsophisticated orthal motion

52 that resulted in a scissor-like (orthal) adduction of the lower jaw (Ostrom, 1964, 1966; Tanoue et

53 al., 2009).

Food often leaves microscopic traces known as microwear, in the form of pits and scratches on the occlusal surfaces of teeth (Teaford, 1988a, 1991). Comparison of microwear within and among taxa and analyses of scratch orientation have been successfully used to test hypotheses of jaw motion in numerous mammalian taxa (Teaford \& Byrd, 1989; Teaford, 1991; 
58 Charles et al., 2007), as well as various dinosaur groups (Weishampel, 1984; Upchurch \&

59 Barrett, 2000; Rybczynski \& Vickaryous, 2001; Williams, Barrett \& Purnell, 2009; Whitlock,

60 2011; Mallon \& Anderson, 2014; Ősi et al., 2014). Unlike mammalian teeth, each neoceratopsian

61 tooth possessed a single, relatively flat, near vertical occlusal surface resulting from shear

62 between the maxillary and mandibular dentitions (Hatcher et al., 1907; Dodson, Forster \&

63 Sampson, 2004). Occlusal microwear on ceratopsian teeth is the result of the direction and

64 magnitude of the jaw closing power stroke of mastication, and an exceptional record of jaw

65 action is recorded on teeth as a result of the planar nature of the occlusal surface. Given a strictly

66 orthal model, predicted microwear should be composed of striations that are rectilinear and

67 limited to a single modality at or near the apicobasal axis of the tooth. To test this hypothesis,

68 dental microwear was examined in the non-ceratopsid neoceratopsian Leptoceratops gracilis, B.

69 Brown (Brown, 1914).

\section{Materials \& Methods}

Dental microwear was examined in a nearly complete, articulated skull of the

neoceratopsian Leptoceratops gracilis (CMN 8889; Canadian Museum of Nature, Ottawa,

74 Ontario, Canada) as well as the holotype material (AMNH FR 5205; American Museum of

75 Natural History, New York, New York, USA) and isolated teeth $(\mathrm{n}=2)$ assigned to the taxon

76 (YPM VPPU 018133; Yale Peabody Museum of Natural History, New Haven, Connecticut,

77 USA). The conclusions in this analysis are derived primarily from examination of CMN 8889.

78 AMNH FR 5205 and YPM VPPU 018133 were examined to provide qualitative support for

79 conclusions drawn from CMN 8889; they were not quantitatively analysed because preserved 
80 microwear was either of slightly lesser quality and did not provide a large sample size (AMNH

81 FR 5205) or represented isolated teeth (YPM VPPU 018133).

82 Each tooth was molded using Coltene President surface activated polyvinylsiloxane

83 molding compound. This compound is available in multiple thicknesses, and the President Jet

84 regular (product number C6012) was used to obtain peels of occlusal surfaces, whereas the

85 President impression putty (product number C4843) was used to create walls around the edge of

86 peels, transforming them into cups capable of receiving epoxy resin. Prior to molding, teeth were

87 screened for alterations and artifacts that can occur due to taphonomic, post depositional, and

88 museum conservation processes. Teeth from all specimens included here were deemed suitable

89 for analysis because they met a number of criteria suggested by other workers as indicative of

90 genuine microwear. Microwear on the Leptoceratops sample is relatively uniform, having a

91 regular pattern and showing no evidence of multiple abrupt shifts or large gouges indicative of

92 preparation marks (Teaford, 1988b). Striations are well defined and show none of the

93 obliteration and dulling characteristic of taphonomic particulate abrasion or acid etching

94 (Teaford, 1988b; King, Andrews \& Boz, 1999). When preservative obscuring occlusal surfaces

95 was encountered, it was removed using a gentle scrubbing action with cotton swabs and acetone

96 or ethanol as the solvent.

97 Casts were poured using a two-part epoxy resin (EPO-TECH \#301) designed to cure

98 slowly at room temperature with minimal exothermal heat production. Casts were allowed to

99 cure for $14-21$ days at $\approx 23^{\circ} \mathrm{C}$. Upon solidification, casts were removed from their molds and

100 secured to SEM specimen mounts (SPI Supplies ${ }^{\circledR}$ Aluminum Pin-Type Mounts \#1507L-MB)

101 using a nonconductive modified nitrocellulose solution (Duco Cement $\left.{ }^{\circledR}\right)$. Casts were then gold-

102 palladium coated for 180 seconds using a Denton Vacuum Desk III set to 40 milliamps and a 
$10350 \%$ Argon gas mixture. Silver paint (SPI Supplies ${ }^{\circledR}$, Ag Colloidal Suspension \#05001-AB) was

104 used to create a conductive connection between the coated specimen and SEM mount, ensuring 105 electron transmission.

106 Microscopic examination was conducted using an Amray 1810 scanning electron

107 microscope set to a working distance of $11 \mathrm{~mm}$, and a $20-\mathrm{keV}$ electron beam in secondary

108 emission mode. The occlusal surface was oriented orthogonal to the electron beam to provide a

109 controlled position. This, coupled with the secondary emission mode, helped to minimize the

110 extinction of features that can occur with tilting and use of backscatter electrons (Galbany,

111 Martinez \& Perez-Perez, 2004). Specimens were photographed at 100X using Polaroid®,

112 Polapan 55 film (ISO 50/18 $20 \mathrm{sec} . / \mathrm{Sek} / \mathrm{s}$ ), and micrographs were scanned as bit-map images at

113 a resolution of 300 dpi for computer analysis.

114 Wear features were digitized using Microware, Version 4.02, a semi-automated image

115 analysis system for the quantification of dental microwear (Ungar, 2002). Microware 4.02

116 records features as four points ( $\mathrm{x}, \mathrm{y}$ coordinates) on a Cartesian grid as the user defines the length

117 and width of a feature by clicking on its ends with a computer mouse. These Cartesian data were

118 imported into a Microsoft Excel spreadsheet, and a macro (Article S1, S2) was written to

119 trigonometrically calculate the angle of microwear striations within a $180^{\circ}$ arc progressing from

120 apical to basal on the distal side of the tooth.

121 Individual teeth were examined separately, because whole jaws cannot fit into the SEM

122 chamber. This necessitated directional standardization within the chamber so that micrographs

123 and angular data would be consistent and comparable among teeth. The primary ridge of the

124 tooth crown is a prominent feature common to all teeth, and its orientation was assumed to be

125 near apicobasal. The apex of the tooth was oriented to the left using this ridge and micrographs 
126 were then photographed in this position. Some micrographs were flipped horizontally using

127 Adobe Photoshop prior to digitization with Microware 4.02 to obtain angular data directly

128 comparable and easily visualized for all teeth in all quadrants of the dentition. Micrographs from

129 teeth in the right dentary quadrant were designated as the standard and all other quadrants

130 manipulated to provide data comparable with this quadrant. Left dentary and right maxillary

131 micrographs were flipped horizontally. Left maxillary teeth did not require manipulation because

132 angles measured from this quadrant are the same as those in the right dentary. This protocol

133 produced comparable angles without the need for mathematical transformation via the

134 trigonometric principle that alternate interior angles are equal. Analyses of angular data (Data

135 S1) were conducted using Oriana, Version 2.0 (Kovach, 2003), a circular statistics and rose

136 diagram software package. Oriana was used to generate rose diagrams, calculate mean angle,

137 Rao's spacing test, and length of the mean vector $(\boldsymbol{r})$. Rose diagrams depict angular data on a

138 unit circle with increasing angle as a function of clockwise rotation. As such, all rose diagrams

139 herein depict angles relative to wear on a left dentary tooth of a left facing skull, facilitating

140 direct visual comparison among dental quadrants. In all rose diagrams $90^{\circ}$ is equivalent to the

141 caudal direction and $180^{\circ}$ is ventral.

$142 r$ and Mean Angle-The homogeneity of scratch orientations can be measured by the

143 value $r$, which is the length of the mean vector of circularly-distributed data on a unit circle with

144 an imaginary radius of 1.0 (Zar, 1998; Mardia \& Jupp, 2000). The mean vector is inversely

145 proportional to uniformity, with values ranging from 0 to 1.0. Values of $\boldsymbol{r}$ approaching 0 indicate

146 striations whose angles are uniformly dispersed around the circle, whereas those approaching 1.0

147 indicate angles with high homogeneity confined to a relatively small angular arc. The following

148 formula describes $\boldsymbol{r}$ : 


$$
r=\frac{1}{n} \sqrt{\left(\sum_{i=1}^{n} \cos \theta_{i}\right)^{2}+\left(\sum_{i=1}^{n} \sin \theta_{i}\right)^{2}}
$$

where $n$ is the sample size and $\theta$ is the angle of the $i^{\text {th }}$ striation. Because a single axis can be

151 described by two different angles $180^{\circ}$ apart, using these data in the above equation without

152 transformation would yield an $\boldsymbol{r}$ value lower than expected. For example, two striations with

153 angles $10^{\circ}$ and $190^{\circ}$ are parallel to each other and striking in the same direction, thus an $\boldsymbol{r}$ value

154 of 1.0 is expected. However, these values yield an $\boldsymbol{r}=0$ when inserted into the equation because

155 they are on opposite sides of the unit circle and thus evenly distributed. For axial data, all angles

156 are doubled (multiplied by 2), and any angle greater than or equal to $360^{\circ}$ is subtracted by $360^{\circ}$.

157 This transformation has the effect of rotating any angle of $\theta$ that is in the $180-359^{\circ}$ hemisphere

158 back into the $0-179^{\circ}$ hemisphere so that it is equal to its counterparts in that half of the circle, and

159 yielding a correct $\boldsymbol{r}$ value. The mean angle can then be found using the mean sine and cosine

160 values calculated above for the length of the mean vector, using the inverse tangent function:

$$
\bar{\theta}=\tan ^{-1}\left(\sum_{i=1}^{n} \sin \theta_{i}\right) /\left(\sum_{i=1}^{n} \cos \theta_{i}\right)
$$

162 Because of the doubling of angles for the $\boldsymbol{r}$ calculation above, the angle resulting from this 163 equation should be halved to arrive at the correct mean angle.

164 Rao's Spacing L-Test-Rao's spacing test evaluates the null hypothesis that a sample of 165 angles is uniformly distributed around a circle (Mardia \& Jupp, 2000). A value less than the 166 predetermined significance level rejects the null hypothesis and supports the alternative, that the 167 angles show a preferred direction. This test was chosen because it is more powerful when 168 confronted with bimodal data separated by $180^{\circ}$, compared to other similar tests such as the 
169 Rayleigh test of uniformity. The Rayleigh test incorporates $r$ in calculating its test statistic $\mathrm{Z}$

$170\left(\mathrm{Z}=n r^{2}\right)$. Because bimodal data on opposite sides of the circle yield low $r$ values, the $\mathrm{Z}$ value

171 would be proportionately small. Small $\mathrm{Z}$ values fail to reach the given level of significance $(\mathrm{p}=$

172 0.05), increasing the likelihood of a type II error, which would fail to reject the null hypothesis.

173 Rao's spacing does not use $r$, but instead examines the spacing between points on the unit circle

174 and compares their deviation from the uniform case where the spacing should be $2 \pi / \mathrm{n}$ radians

$175\left(360^{\circ} / \mathrm{n}\right)$. The L statistic is calculated:

$$
L=\frac{1}{2} \sum_{i=1}^{n}\left|T_{i}-\frac{2 \pi}{n}\right|
$$

where $n$ is the sample size, and $T_{i}$ is the spacing or difference between the observed angles given

178 the following:

$$
T_{i}=\theta_{(i)}-\theta_{(i-1)}, \quad i=1, \ldots, n-1, \quad T_{n}=2 \pi-\left(\theta_{(n)}-\theta_{(1)}\right)
$$

180 Because $T_{i}$ is the distance between $n$ observed points and $2 \pi / \mathrm{n}$ is the expected distance between $n$

181 points then the difference between them should be large if the observed points are clustered, thus 182 yielding a large value of $L$.

\section{Results}

Microwear striations on teeth of Leptoceratops (CMN 8889) conform to predictions of orthal chewing by being unimodal in distribution (Fig. 1). However, they differ greatly in other parameters. Striations are not rectilinear, as would be expected of a simple scissor-like closure of the mandible, but are curvilinear (Figs. 2A-B, 3). Striations begin at the apicodistal border on dentary teeth and curve though an arc of nearly $50^{\circ}$ before ending in either a horizontal or apicomesial orientation near the mesial border (Figs. 2A, 3A-B). Maxillary teeth show a 
191 counterpart curvature, with striations beginning apicomesially and ending distal to apicodistally

192 (Figs. 2B, 3C-D).

193 As a result of this curvature, angular measurements from multiple locations on the

194 occlusal surface yield different values and are thus not directly comparable. To foster

195 comparability, measurements were taken from micrographs imaged near the apicodistal limit of

196 dentary teeth and the apicomesial edge of maxillary teeth, where the beginning phase of the

197 power stroke initiates microwear formation. The occlusal surface of Leptoceratops teeth is

198 composed of the enamel, hard mantle dentine, and orthodentine materials discussed by Erickson

199 and others (2015). Microwear is formed in, and traverses all of these tissues, but only a thin rim

200 of enamel encapsulates the edge (cutting edge) of the occlusal surface, As such, most of the

201 occlusal surface is hard mantle dentine and orthodentine. As mentioned above, micrographs were

202 taken near the apicodistal and apicomesial edges of teeth, resulting in capture of microwear

203 formed primarily in orthodentine and some hard mantle dentine. Microwear can be seen to

204 traverse materials of differing hardness without appreciable shift in direction (Fig. 2A\&C).

205 A Rao's spacing test was performed on angular measurements from each tooth (Table 1),

206 and in all cases a uniform distribution of measurements about a $360^{\circ}$ circle is rejected $(\mathrm{p}<0.01)$,

207 supporting a preference for the mean direction. Furthermore, striations are not oriented with or

208 near the apicobasal axis of the tooth but are inclined distally relative to it. This distal inclination

209 is consistent across all teeth examined with means from individual teeth ranging from $26-55^{\circ}$

210 (Table 1; Figs. 2C-F, 4).

211 Many striations traverse the entire occlusal surface unbroken, indicating that each was

212 caused by particulates being dragged continuously across the tooth surface (Figs. 2A-B, 3).

213 Striations also show a high length of the mean vector $(\boldsymbol{r})$, ranging from 0.53 to 0.99 for 
214 individual teeth (Table 1; Figs. 2E-F, 4). Length of the mean vector is a statistic that summarizes

215 the parallelism of scratches. If all scratches are nearly parallel, or have a similar angular

216 orientation, then the value of $\boldsymbol{r}$ approaches one, if they are more randomly distributed then this

217 value approaches zero (Zar, 1998; Mardia \& Jupp, 2000).

218 Microwear preserved on additional specimens of Leptoceratops (AMNH FR 5205, YPM

219 VPPU 018133) corroborates qualitative observations made on CMN 8889. An isolated right

220 maxillary tooth assigned to Leptoceratops (YPM VPPU 018133) shows dental microwear with

221 an apicomesial (rostroventral) orientation near the site of powerstroke initiation, and striations

222 curve through a similar arc to end in a mesiodistal (rostrocaudal) orientation (Compare Fig. 5A

223 with Fig. 2A). Teeth from AMNH FR 5205 show multiple stages of wear. On some teeth,

224 microwear is interrupted by preparation marks, broken crowns, or what appear to be root

225 erosions. Some microwear is visible on the occlusal surface of the fifth right dentary tooth (Fig.

226 5B), despite missing the apex and mesial half of the crown. The dominant wear grain consists of

227 striations oriented parallel to subparallel with the mesiodistal axis, and showing a slight change

228 in curvature. The wear also reflects a similar orientation as the nearby labial shelf (LS).

229 Considering this structure as a result of differential wear via incomplete shear of maxillary teeth

230 against their dentary counterparts, its orientation should be similar to nearby microwear on the

231 occlusal surface.

232

233 Discussion \& Conclusions

234 The inclination and curvilinear character of microwear striations is entirely inconsistent

235 with the standard orthal model (Ostrom, 1964; Tanoue et al., 2009) of neoceratopsian

236 mastication. A significant Rao's spacing test supports a power stroke that was directed along the 
237 mean striation angle. To traverse an unbroken arc, the mandible must have undergone

238 uninterrupted precise motion as the dentary teeth slid past the maxillary teeth during the power

239 stroke. Indeed, the high degree of striation parallelism (high $\boldsymbol{r}$ ) indicates a power stroke event

240 that was performed under precise muscular action and one that must have been stereotyped due

241 to the homogenous nature of curvilinear striations. (Figs. 2-5).

242 Refutation of the orthal model of mastication in neoceratopsians requires an alternative

243 with increased explanatory power. Unlike mammals, ceratopsians retained the plesiomorphic

244 organization of jaw adductor muscles present in their amniote ancestors. The $m$. adductor

245 mandibulae externus group and the $m$. adductor mandibulae posterior are the major jaw closing

246 muscles (Haas, 1955; Holliday, 2009). These muscles have caudodorsal vectors, with the former

247 having a stronger dorsal component and the latter a more caudal orientation. The m. pterygoideus

248 group is also involved in jaw closure, having a rostrodorsal vector. However, its role is more

249 pronounced during the beginning of adduction (Carroll, 1969) rather than the power stroke, and a

250 correlate in microwear is undetectable. Microwear at the apicodistal limit of dentary teeth is

251 oriented in the direction of the supratemporal fenestrae, suggesting that the power stroke was

252 initiated by the $m$. adductor mandibulae externus group. Although the $m$. adductor mandibulae

253 externus group would have assisted in retraction of the jaw due to its caudodorsal vector, the

254 muscle of primacy for producing the mesiodistally oriented microwear at the basomesial edge of

255 dentary teeth was the $m$. adductor mandibulae posterior. Production of the uniform arc seen on

256 these teeth must have involved a precise yet smooth transition between actions of the $m$.

257 adductor mandibulae externus group and the m. adductor mandibulae posterior (Fig. 6).

258 Microwear in Leptoceratops supports a model of mastication where the initiation of the

259 power stroke was simultaneously orthal and palinal. Propalinal motion has been proposed in 
260 various ornithopods, and the sauropod Diplodocus (Ostrom, 1961; Barrett \& Upchurch, 1994;

261 Williams, Barrett \& Purnell, 2009; Williams, 2010). Pilot work by Sampson (1993) and Barrett

262 (1998) suggested propalinal motion was present in the derived ceratopsid, Triceratops. However,

263 the mechanism proposed here for Leptoceratops is of a decidedly palinal nature, with no forward

264 motion of the mandible while the teeth are in occlusion. Mallon and Anderson (2014) examined

265 a variety of Campanian hadrosaurids and did not recover the multiple scratch classes indicative

266 of propaliny found by Williams and others (2009), instead, finding only a bimodal distribution

267 with classes in the dorsoventral to caudodorsal direction. They conclude that an orthopalinal

268 powerstroke characterized hadrosaurid mastication. An orthopalinal direction was likewise

269 proposed for Ceratopsidae by Varriale (2011), and his work has been upheld by Mallon and

270 Anderson (2014) who also examined ceratopsid microwear. Whereas the initiation of the

271 powerstroke in Leptoceratops agrees with the orthopalinal models of Varriale (2011) and Mallon

272 and Anderson (2014), the full cycle of the stroke departs strongly. This initial inclined palinal

273 direction has also been demonstrated in the basal ceratopsian Psittacosaurus. Previously, Sereno

274 (1987) and Norman and Weishampel (1991) suggested a propalinal mechanism for

275 Psittacosaurus, with Sereno (1987) forwarding a palinal powerstroke. However, recent work has

276 clarified a more detailed mechanism where inclined dental facets combined with diverging tooth

277 rows and an orthopalinal motion yielded continuous occlusion during the power stroke (Sereno,

278 Xijin \& Lin, 2010). The term clinolineal was coined to encompass the jaw mechanism of

279 Psittacosaurus, because occlusion occurred over an inclined linear direction (Sereno, Xijin \&

280 Lin, 2010). However, microwear produced by clinolineal and orthopalinal chewing is rectilinear

281 and not strongly curved, as that demonstrated here in Leptoceratops. Unlike the condition in

282 Psittacosaurus and derived ceratopsids, the semicircular microwear of Leptoceratops supports a 
283 power stroke that progressed smoothly into a palinal phase (Fig. 6). The term circumpalinal is

284 proposed here to describe the semicircular orbit that is accomplished during the overall palinal

285 (front-to-back) jaw action in Leptoceratops, and to distinguish this style of chewing from the

286 clinolineal and orthopalinal mastication of other ceratopsians.

287 Among dinosaurs, complex mastication may have been achieved through intracranial

288 joints, in a manner very different from that seen in mammals. Euhadrosaurs (duck-billed

289 dinosaurs) have been reconstructed as masticating using pleurokinesis, a unique motion in which

290 the maxillae and associated teeth swung laterally as the mandibular dentition occluded with them

291 (Weishampel, 1984; Norman \& Weishampel, 1985). However, the existence of pleurokinesis is

292 currently contested. The work of Holliday and Witmer (2008) indicates that despite having

293 intracranial synovial joints, hadrosaurids were only partially kinetically competent. Cuthbertson

294 and others (2012) further examined the masticatory apparatus in Brachylophosaurus and

295 Edmontosaurus by scrutinizing dental microwear, arthrology, and kinematic models. They

296 concluded that the facial skeleton of these taxa were akinetic. Still, microwear from the teeth of

297 euhadrosaurs indicates that the jaws may have slid past one another in a pleurokinetic

298 mechanism (Williams, Barrett \& Purnell, 2009). However, it now seems that mandibular long-

299 axis rotation, combined with an orthopalinal powerstroke and accessory propalinal motion, has

300 the greatest explanatory power for interpreting observed microwear (Cuthbertson et al., 2012;

301 Nabavizadeh, 2014; Mallon \& Anderson, 2014).

302 Depending on the phylogenetic position of Heterodontosaurus, basal ornithischians may

303 also have chewed by rotation of the dentary bones about their long axes (Hopson, 1980;

304 Weishampel, 1984), producing an effect similar to pleurokinesis. Crompton and Attridge (1986)

305 rejected mandibular rotation based on the presence of planar wear facets and a mediolaterally 
306 expanded jaw joint. They substituted a mechanism of medial deviation of the mandibular rami by

307 decreasing the lingual angle at the mandibular symphysis. Recently, Norman et al. (2011)

308 contested both mandibular rotation and medial flexion, citing several restrictions that would have

309 prevented these motions, but they did not provide an alternative mechanism. Sereno (2012)

310 questioned some of the restrictions enumerated by Norman et al. (2011), such that the remaining

311 details and further analysis by him supported mandibular rotation with some medial flexion.

312 What little is known of their mastication indicates that each of the major ankylosaur clades

313 may have had their own unique and complex jaw actions. Rybczynski and Vickaryous (2001)

314 showed that mastication in the derived ankylosaurid Euoplocephalus was accomplished by

315 swinging the caudal portion of the dentary bones laterally as a result of translation within the jaw

316 joint. The predentary and dentary bones forming a condyloid joint, permitting medial rotation of

317 the anterior dentary. The combined effect created a propalinal arcing of the mandible with both

318 shearing and crushing abilities (Rybczynski \& Vickaryous, 2001). Ösi and others (2014)

319 examined microwear, jaw architecture, and myology in the nodosaurid Hungarosaurus,

320 reconstructing a different action than that in Euoplocephalus. Microwear on dentary teeth of

321 Hungarosaurus is bimodal with a near apicobasally oriented class that traverses most of the

322 occlusal surface, and a mesiodistal class that is principally located near the base of occlusal

323 facets. They propose that jaw action was initiated with an orthal motion followed by transition

324 into a palinal powerstroke, these actions being assisted by mandibular rotation or medial flexion.

325 The action seen here in Leptoceratops bears some resemblance to that proposed for

326 Hungarosaurus (Ösi et al., 2014); however, there are also some notable departures. The

327 apicobasally/apicodistally oriented microwear on Hungarosaurus dentary teeth does not show a

328 consistent and continuous transition to a mesiodistal orientation. Save for a few scratches 
329 showing a curved transition, the two classes are disconnected, indicating that transition to a

330 palinal stroke was not as smooth as in Leptoceratops, but a discrete event. The proposed chewing

331 cycle for Hungarosaurus bears this out, with orthal and palinal phases depicted as discreet and

332 rapid changes in vector (Ösi et al., 2014). The transition in Leptoceratops was not swift and

333 abrupt, but one spread over the entire powerstroke with the possibility of one muscle group

334 trading action to another. The relatively flat glenoid of Hungarosaurus compared to the deeply

335 cupped joint in Leptoceratops also influences the path a powerstroke can take (see below) and is

336 an additional reason for the departure of action in these two taxa. Nevertheless, the basic jaw

337 action of Hungarosaurus traces a similar, albeit, disjointed path.

338 Apparent from the discussion above is the significant departure of Leptoceratops from all

339 other known models of mastication within Dinosauria. Ceratopsians are entirely lacking in

340 adaptations for cranial kinesis and could not use this type of motion to facilitate mastication.

341 Ceratopsian skulls are tightly sutured, preventing any lateral rotation of the maxillae (Holliday \&

342 Witmer, 2008). Furthermore, the quadrate bones have a tongue and grove association with the

343 squamosals and are buttressed posteriorly by the paraoccipital processes of the exoccipital bones,

344 precluding both pleurokinesis and streptostyly (Dodson, 1993). The mandibles are similarly

345 impaired; in Leptoceratops the caudodorsal process of the predentary bone displays a projection

346 that is tightly locked into a pit at the rostrodorsal end of the dentary (Tanoue, You \& Dodson,

347 2010). Furthermore, the caudoventral processes of the predentary overlap the lateral margins of

348 the dentaries, so that no rotational or translational motion could have occurred between these

349 elements. The quadrate-articular jaw joint is thus the only site available to produce the

350 masticatory orbit recorded in the microwear of Leptoceratops. 
The semicircular character of dental microwear striations in Leptoceratops resulted from a

352 combination of the aforementioned muscular actions directing motion at the jaw joint. As the

353 chewing cycle began, the quadrate started at the caudal rim of the mandibular glenoid, causing

354 apicodistally oriented striations on dentary teeth. When the quadrate reached the base of the

355 glenoid, microwear on teeth transitioned to a mesiodistal orientation, and then to an apicomesial

356 orientation as further adduction caused the quadrate to ride up the rostral wall of the glenoid. An

357 analogous rostrocaudal masticatory orbit within an akinetic skull occurs in several mammalian

358 groups, including multituberculates (Wall \& Krause, 1992), haramiyid allotherians (Butler,

359 2000), and some rodents (Rose, 2006). Palinal occlusion also occured in cynodonts, but

360 microwear and tooth morphology show no evidence of orbital motion of the mandible

361 (Crompton, 1972; Rybczynski \& Reisz, 2001). The presence of mammal-like orbital motion in

362 Leptoceratops is striking because of the structural differences in the jaw joint between dinosaurs

363 and mammals. In mammals, the condyle is on the dentary bone and the glenoid depression is on

364 the underside of the skull in the squamosal. Dinosaurs are essentially the reverse, as they retain

365 the ancestral amniote condition of a condyle on the quadrate of the skull and the glenoid

366 depression in the articular of the lower jaw (Norman \& Weishampel, 1991). This retention of the

367 ancestral condition suggests that complex motion of the lower jaw, involving multiple vectors in

368 an orbital motion, need not require a mammalian jaw architecture for its development, and it

369 broadens our understanding of comparative biomechanics.

370 The greatest biodiversity of ceratopsians occurs during the latter half of the Cretaceous, a

371 time known for the diversification and revolution of terrestrial communities by angiosperm

372 plants (Lloyd et al., 2008). However, recent investigations have questioned or shown no

373 correlation in diversification between dinosaur groups and angiosperms (Weishampel \& Jianu, 
374 2000; Barrett \& Willis, 2001; Lloyd et al., 2008; Butler et al., 2010). The recognition of a novel

375 chewing adaptation in a ceratopsian dinosaur suggests that previous assignments (Weishampel \&

376 Norman, 1989; Weishampel \& Jianu, 2000) of taxa to masticatory groupings (orthal pulper,

377 orthal slicer, etc.) may have been too gross. The disparate chewing mechanisms of

378 Euoplocephalus and Hungarosaurus coupled with a depauperate understanding of chewing in

379 other ankylosaurs demonstrates the need for refining the details of jaw action in herbivorous

380 dinosaurs. This refinement, in addition to other areas of inquiry (sampling bias, spatio-temporal

381 diversity and abundance) may bring much needed resolution to the ongoing question of

382 angiosperm-dinosaur coevolution.

383 The discovery of circumpalinal mastication in a ceratopsian that has been known for over

384100 years provokes questions concerning the distribution of this jaw action. Like clinolineal

385 mastication in psittacosaurids (Sereno, Xijin \& Lin, 2010), is circumpalinal chewing relatively

386 scarce, limited to Leptoceratops or Leptoceratopsidae, or does it have much wider distribution

387 within Ceratopsia? One of the specimens examined here suggests, at least, a leptoceratopsid

388 distribution. YPM VPPU 018133 was considered by Ostrom (1978) to be Leptoceratops gracilis,

389 but Chinnery (2004) suggested a possible assignment to Prenoceratops based on stratigraphic

390 grounds (the fossil was from the Meeteetse Formation, potentially older than the rocks that yield

391 L. gracilis). Regardless of the assignment of this material, at a minimum it corroborates

392 circumpalinal mastication in Leptoceratops gracilis, and at most hints at a wider distribution of

393 this chewing style within Leptoceratopsidae.

394 Recent work also addresses the question of wider distribution, and indicates that

395 circumpalinal mastication was not present in derived ceratopsids (Varriale, 2011; Mallon \&

396 Anderson, 2014). However, this leaves a large paraphyletic portion of Ceratopsia for which jaw 
397 action is unknown, and as such the ancestral action for all ceratopsians is also unknown.

398 Clinolineal mastication could extend to the base of Ceratopsia or be limited to Psittacosauridae.

399 If limited, then circumpalinal or orthopalinal mastication may be the ancestral conditions. A

400 fourth, as yet undiscovered action may be present there, or the orthal mechanism that seems to be

401 present in the ceratopsian outgroup Pachycephalosauria (Sues \& Galton, 1987; Varriale, 2015)

402 and many other ornithischians (Thulborn, 1971; Weishampel, 1984; Crompton \& Attridge, 1986;

403 Norman \& Weishampel, 1991; Barrett, 1998, 2001), could have been retained at the ceratopsian

404 base. To further support the results here for Leptoceratops, and answer the aforementioned

405 questions, a much wider range of taxa will need to be sampled, including other non-ceratopsid

406 neoceratopsians as well as basal ceratopsians outside of Psittacosauridae. This expanded analysis

407 is currently underway by F. Varriale.

408 Recognition of circumpalinal chewing within Leptoceratops adds a distinct style of

409 mastication to the dinosaurian repertoire, one that is fundamentally different from previously

410 understood mechanisms involving cranial or mandibular kinesis. This suggests that some

411 dinosaurs may have possessed a mammalian level of masticatory prowess and biomechanical

412 diversity, achieving this convergence through novel independent adaptations of the masticatory 413 apparatus. 


\section{Acknowledgements}

415 Thanks to Andrew Farke, Jordan Mallon, David Weishampel, and Mark Teaford for comments

416 and discussion that improved initial drafts of this manuscript. Paul Barrett and Jeremy Green

417 provided thorough and insightful reviews that enhanced the quality the narrative. Walter Joyce

418 (YPM), Carl Mehling (AMNH), Natalia Rybczynski (CMN), and Kieran Shephard (CMN)

419 provided access to specimens.

420

421

422

423

424

425

426

427

428

429

430

431

432

433

434

435

436

437

\section{References}

Angielczyk KD. 2004. Phylogenetic evidence for and implications of a dual origin of propaliny in anomodont therapsids (Synapsida). Paleobiology 30:268-296. DOI: 10.1666/00948373(2004)030<0268:PEFAIO>2.0.CO;2.

Barrett PM. 1998. Herbivory in the Non-Avian Dinosauria. Ph.D. Dissertation Thesis. United Kingdom: University of Cambridge.

Barrett PM. 2001. Tooth wear and possible jaw action of Scelidosaurus harrisonii Owen and a review of feeding mechanisms in other thyreophoran dinosaurs. In: Carpenter $\mathrm{K}$ ed. The Armored Dinosaurs. Bloomington, Indiana: Indiana University Press, 25-52.

Barrett PM., Upchurch P. 1994. Feeding mechanisms of Diplodocus. Gaia 10:195-203.

Barrett PM., Willis KJ. 2001. Did dinosaurs invent flowers? Dinosaur-angiosperm coevolution revisited. Biological Reviews 76:411-447. DOI: 10.1017/S1464793101005735.

Brown B. 1914. Leptoceratops, a new genus of Ceratopsia from the Edmonton Cretaceous of Alberta. Bulletin of the American Museum of Natural History 33:567-580.

Butler PM. 2000. Review of the early allotherian mammals. Acta Palaeontologica Polonica 45:317-342. 
438 Butler RJ., Barrett PM., Penn MG., Kenrick P. 2010. Testing coevolutionary hypotheses over 439 geological timescales: interactions between Cretaceous dinosaurs and plants. Biological 440 441 Carroll RL. 1969. Problems of the Origin of Reptiles. Biological Reviews 44:393-431. DOI: 442 10.1111/j.1469-185X.1969.tb01218.x.

443 Charles C., Jaeger J-J., Michaux J., Viriot L. 2007. Dental microwear in relation to changes in 444 the direction of mastication during the evolution of Myodonta (Rodentia, Mammalia). Die Naturwissenschaften 94:71-5. DOI: 10.1007/s00114-006-0161-7.

446 Chinnery B. 2004. Description of Prenoceratops pieganensis gen. et sp. nov. (Dinosauria: Neoceratopsia) from the Two Medicine Formation of Montana. Journal of Vertebrate Paleontology 24:572-590. DOI: 10.2307/4524748.

Cox CB. 1998. The jaw function and adaptive radiation of the dicynodont mammal-like reptiles 450 of the Karoo basin of South Africa. Zoological Journal of the Linnean Society 122:349384. DOI: 10.1111/j.1096-3642.1998.tb02534.x.

Crompton AW. 1972. The evolution of the jaw articulation in cynodonts. In: Joysey KA, Kemp 453 TS eds. Studies in Vertebrate Evolution. Edinburgh: Oliver and Boyd, 231-251.

Crompton AW., Attridge J. 1986. Masticatory apparatus of the larger herbivores during Late York, USA: Cambridge University Press, 223-236. dicynodonts (Reptilia, Therapsida). Postilla 109:1-51. 
460 Cuthbertson RS., Tirabasso A., Rybczynski N., Holmes RB. 2012. Kinetic Limitations of 461 Intracranial Joints in Brachylophosaurus canadensis and Edmontosaurus regalis 462 (Dinosauria: Hadrosauridae), and Their Implications for the Chewing Mechanics of 463 Hadrosaurids. The Anatomical Record: Advances in Integrative Anatomy and 464 Evolutionary Biology 295:968-979. DOI: 10.1002/ar.22458.

465 Dodson P. 1993. Comparative craniology of the Ceratopsia. American Journal of Science 466 293:200-234. DOI: 10.2475/ajs.293.A.200.

467 468 469

Dodson P., Forster CA., Sampson SD. 2004. Ceratopsidae. In: Weishampel DB, Dodson P, Osmólska H eds. The Dinosauria. Berkeley, California: University of California Press, 494-513.

Erickson GM., Krick BA., Hamilton M., Bourne GR., Norell MA., Lilleodden E., Sawyer WG. 2012. Complex dental structure and wear biomechanics in hadrosaurid dinosaurs. Science 338:98-101. DOI: 10.1126/science.1224495.

Erickson GM., Sidebottom MA., Kay DI., Turner KT., Ip N., Norell MA., Sawyer WG., Krick BA. 2015. Wear biomechanics in the slicing dentition of the giant horned dinosaur Triceratops. Science Advances 1. DOI: 10.1126/sciadv.1500055.

Galbany J., Martinez LM., Perez-Perez A. 2004. Tooth replication techniques, SEM imaging and microwear analysis in Primates: methodological obstacles. Anthropologie 42:5-12.

Haas G. 1955. The jaw musculature in Protoceratops and in other ceratopsians. American Museum Novitates 1729:1-24.

Hatcher JB., Marsh OC., Lull RS., Osborn HF. 1907. The ceratopsia. Monographs of the United States Geological Survey 49:1-300. 
482 Hiiemae KM. 2000. Feeding in mammals. In: Schwenk K ed. Feeding: Form, Function and 483 Evolution in Tetrapod Vertebrates. San Diego, California: Academic Press, 411-448. 484 Holliday CM. 2009. New insights into dinosaur jaw muscle anatomy. Anatomical Record 485 292:1246-1265. DOI: 10.1002/ar.20982.

486 487

488

489

490

491

492

493

494 495

496

497

498

499

500

501

502

503

504

Holliday CM., Witmer LM. 2008. Cranial kinesis in dinosaurs: intracranial joints, protractor muscles, and their significance for cranial evolution and function in diapsids. Journal of Vertebrate Paleontology 28:1073-1088. DOI: 10.1671/0272-4634-28.4.1073.

Hopson JA. 1980. Tooth function and replacement in early Mesozoic ornithischian dinosaurs: implications for aestivation. Lethaia 13:93-105. DOI: 10.1111/j.15023931.1980.tb01035.x.

King GM. 1990. Dicynodonts: A Study in Palaeobiology. London, United Kingdom: Chapman and Hall.

King GM. 1996. Reptiles and Herbivory. London, United Kingdom: Chapman and Hall.

King T., Andrews P., Boz B. 1999. Effect of taphonomic processes on dental microwear. American Journal of Physical Anthropology 108:359-373. DOI: 10.1002/(SICI)10968644(199903)108:3<359::AID-AJPA10>3.0.CO;2-9.

King GM., Oelofsen BW., Rubidge BS. 1989. The evolution of the dicynodont feeding system. Zoological Journal of the Linnean Society 96:185-211. DOI: 10.1111/j.10963642.1989.tb01826.x.

Kovach WL. 2003. Oriana - circular statistics for Windows. Pentraeth, Wales, U.K: Kovach Computing Services.

Lloyd GT., Davis KE., Pisani D., Tarver JE., Ruta M., Sakamoto M., Hone DW., Jennings R., Benton MJ. 2008. Dinosaurs and the Cretaceous terrestrial revolution. Proceedings of the 
Royal Society of London B: Biological Sciences 275:2483-2490. DOI:

506 10.1098/rspb.2008.0715.

507 Mallon JC., Anderson JS. 2014. The functional and palaeoecological implications of tooth 508 morphology and wear for the megaherbivorous dinosaurs from the Dinosaur Park Formation (upper Campanian) of Alberta, Canada. PloS ONE 9:e98605-e98605. DOI: 10.1371/journal.pone.0098605.

511 Mardia KV., Jupp PE. 2000. Directional Statistics. Chichester, West Sussex, United Kingdom: John Wiley and Sons.

513 Nabavizadeh A. 2014. Hadrosauroid jaw mechanics and the functional significance of the predentary bone. In: Eberth DA, Evans DC eds. Hadrosaurs. Bloomington, Indiana,

516 Norman DB., Crompton AW., Butler RJ., Porro LB., Charig AJ. 2011. The Lower Jurassic

Norman DB., Weishampel DB. 1985. Ornithopod feeding mechanisms: their bearing on the evolution of herbivory. The American Naturalist 126:151-164. DOI: 10.1086/284406.

Norman DB., Weishampel DB. 1991. Feeding mechanisms in some small herbivorous dinosaurs: processes and patterns. In: Rayner JMV, Wootton RJ eds. Biomechanics in Evolution. Cambridge, United Kingdom: Cambridge University Press, 161-181.

O’Connor PM., Sertich JJW., Stevens NJ., Roberts EM., Gottfried MD., Hieronymus TL., Jinnah ZA., Ridgely R., Ngasala SE., Temba J. 2010. The evolution of mammal-like 
crocodyliforms in the Cretaceous Period of Gondwana. Nature 466:748-751. DOI:

528 10.1038/nature09061.

529 Ösi A., Barrett PM., Földes T., Tokai R. 2014. Wear pattern, dental function, and jaw mechanism in the Late Cretaceous ankylosaur Hungarosaurus. The Anatomical Record 297:1165-1180. DOI: 10.1002/ar.22910.

532

533

534

535

536

537

538

539

540

541

542

543

544

545

546

547

548

Ösi A., Weishampel DB. 2009. Jaw mechanism and dental function in the Late Cretaceous basal eusuchian Iharkutosuchus. Journal of Morphology 270:903-920. DOI: 10.1002/jmor. 10726 .

Ostrom JH. 1961. Cranial morphology of the hadrosaurian dinosaurs of North America. Bulletin of the American Museum of Natural History 122:33-186.

Ostrom JH. 1964. A functional analysis of jaw mechanics in the dinosaur Triceratops. Postilla $88: 1-35$.

Ostrom JH. 1966. Functional morphology and evolution of the ceratopsian dinosaurs. Evolution 20:290-308. DOI: 10.2307/2406631.

Ostrom JH. 1978. Leptoceratops gracilis from the "Lance" Formation of Wyoming. Journal of Paleontology 52:697-704. DOI: 10.2307/1303974.

Rose KD. 2006. The Beginning of the Age of Mammals. Baltimore, Maryland: Johns Hopkins University Press.

Rybczynski N., Reisz RR. 2001. Earliest evidence for efficient oral processing in a terrestrial herbivore. Nature 411:684-687. DOI: 10.1038/35079567.

Rybczynski N., Vickaryous MK. 2001. Evidence of complex jaw movement in the Late Cretaceous ankylosaurid Euoplocephalus tutus (Dinosauria: Thyreophora). In: Carpenter 
K ed. The Armored Dinosaurs. Bloomington, Indiana: Indiana University Press, 299317.

551 Sampson SD. 1993. Cranial Ornamentations in Ceratopsid Dinosaurs: Systematic, Behavioural,

552

553

554

555

556

557

558

559

560

561

562

563

564

565

566

567

568

569

570 and Evolutionary Implications. Ph.D. Dissertation Thesis. Toronto, Ontario, Canada: University of Toronto.

Sereno PC. 1987. The Ornithischian Dinosaur Psittacosaurus from the Lower Cretaceous of Asia and the Relationships of the Ceratopsia. Ph.D. Dissertation Thesis. New York, New York USA: Columbia University.

Sereno PC. 2012. Taxonomy, morphology, masticatory function and phylogeny of heterodontosaurid dinosaurs. ZooKeys 226:1-225. DOI: 10.3897/zookeys.226.2840.

Sereno PC., Xijin Z., Lin T. 2010. A new psittacosaur from Inner Mongolia and the parrot-like structure and function of the psittacosaur skull. Proceedings of the Royal Society, Series B: Biological Sciences 277:199-209. DOI: 10.1098/rspb.2009.0691.

Sues H-D., Galton PM. 1987. Anatomy and classification of the North American Pachycephalosauria (Dinosauria: Omithischia). Palaeontographica, Abteilung A 198:140.

Tanoue K., Grandstaff BS., You H-L., Dodson P. 2009. Jaw mechanics in basal ceratopsia (Ornithischia, Dinosauria). Anatomical Record 292:1352-1369. DOI: 10.1002/ar.20979.

Tanoue K., You H-L., Dodson P. 2010. Mandibular anatomy in basal Ceratopsia. In: Ryan MJ, Chinnery-Allgeier BJ, Eberth DA eds. New Perspectives on Horned Dinosaurs: The Royal Tyrell Museum Ceratopsian Symposium. Bloomington, Indiana, USA: Indiana University Press, 234-250. 
571 Teaford MF. 1988a. A review of dental microwear and diet in modern mammals. Scanning

$572 \quad$ Microscopy 2:1149-1166.

573 Teaford MF. 1988b. Scanning electron microscope diagnosis of wear patterns versus artifacts on 574 fossil teeth. Scanning Microscopy 2:1167-1175.

575 Teaford MF. 1991. Dental microwear: what can it tell us about diet and dental function? In:

$576 \quad$ Kelley MA, Larsen CS eds. Andvances in Dental Anthropology. New York, New York:

$577 \quad$ Wiley, 341-356.

578 Teaford MF., Byrd KE. 1989. Differences in tooth wear as an indicator of changes in jaw

579 movement in the guinea pig Cavia porcellus. Archives of Oral Biology 34:929-936. DOI:

$580 \quad 10.1016 / 0003-9969(89) 90048-4$.

581 Thulborn RA. 1971. Tooth wear and jaw action in the Triassic ornithischian dinosaur

582 Fabrosaurus. Journal of Zoology 164:165-179. DOI: 10.1111/j.1469-

583 7998.1971.tb01303.x.

584 Ungar PS. 2002. Microware software. Version 4.02. A semi-automated image analysis system for

585 the quantification of dental microwear. Fayetteville, Arkansas: Unpublished.

586 Upchurch P., Barrett PM. 2000. The evolution of sauropod feeding mechanisms. In: Sues H-D

587 ed. Evolution of Herbivory in Terrestrial Vertebrates: Perspectives from the Fossil

588 Record. Cambridge, United Kingdom: Cambridge University Press, 79-122.

589 Varriale FJ. 2011. Dental Microwear and the Evolution of Mastication in the Ceratopsian

590 Dinosaurs. Ph.D. Dissertation Thesis. Baltimore, Maryland, USA: Johns Hopkins

$591 \quad$ University: School of Medicine. 
592 Varriale FJ. 2015. Dental microwear in Pachycephalosaurus and Stegoceras supports orthal 593 mastication in Pachycephalosauria (Ornithischia). Journal of Vertebrate Paleontology, $594 \quad$ Program and Abstracts 35:230.

595 Wall CE., Krause DW. 1992. A biomechanical analysis of the masticatory apparatus of Ptilodus 596 (Multituberculata). Journal of Vertebrate Paleontology 12:172-187.

597 Weishampel DB. 1984. Evolution of jaw mechanisms in ornithopod dinosaurs. Advances in 598 Anatomy, Embryology, and Cell Biology 87:1-109. DOI: 10.1007/978-3-642-69533-9.

599 Weishampel DB., Jianu C-M. 2000. Plant-eaters and ghost lineages: dinosaurian herbivory

600 revisited. In: Sues H-D ed. Evolution of Herbivory in Terrestrial Vertebrates:

601

602 Perspectives from the Fossil Record. Cambridge, United Kingdom: Cambridge University Press, 123-143.

Weishampel DB., Norman DB. 1989. Vertebrate herbivory in the Mesozoic; Jaws, plants, and 606 607 608 609 evolutionary metrics. Geological Society of America Special Papers 238:87-101. DOI: 10.1130/SPE238-p87.

Whitlock JA. 2011. Inferences of diplodocoid (Sauropoda: Dinosauria) feeding behavior from snout shape and microwear analyses. PLOS ONE 6:e18304. DOI: 10.1371/journal.pone.0018304.

Williams VS. 2010. Tooth Microwear, Diet and Feeding in Ornithischian Dinosaurs. Ph.D. Dissertation Thesis. Leicester, United Kingdom: University of Leicester.

611 Williams VS., Barrett PM., Purnell MA. 2009. Quantitative analysis of dental microwear in 612 hadrosaurid dinosaurs, and the implications for hypotheses of jaw mechanics and feeding. 613 Proceedings of the National Academy of Sciences 106:11194-11199. DOI:

614 10.1073/pnas.0812631106. 
615 Zar JH. 1998. Biostatistical Analysis. Saddle River, New Jersey: Pearson Prentice Hall.

616

617 
618 Table 1: Summary and inferential statistics for angular data from teeth examined in 619 Leptoceratops gracilis (CMN 8889).

$620 \mathrm{LD}=$ left dentary, $\mathrm{LM}=$ left maxillary, $\mathrm{RD}=$ right dentary, and $\mathrm{RM}=$ right maxillary. Alveolar 621 position of each tooth from rostral is indicated by number.

622

\begin{tabular}{|c|c|c|c|c|c|c|c|c|c|c|}
\hline $\begin{array}{l}\text { Maxillary } \\
\text { Teeth } \\
\end{array}$ & LM5* & LM6 & LM7 & LM13* & RM2* & RM3* & RM4 & RM10 & RM11 & RM13* \\
\hline $\mathbf{N}$ & 142 & 100 & 130 & 104 & 37 & 71 & 84 & 103 & 39 & 8 \\
\hline Mean $\theta^{\circ}$ & 43.56 & 47.15 & 26.85 & 39.63 & 31.23 & 38.66 & 40.63 & 35.3 & 34.87 & 46.6 \\
\hline $\begin{array}{l}\text { Length of } \\
\theta^{\circ}(r)\end{array}$ & 0.686 & 0.646 & 0.533 & 0.833 & 0.98 & 0.867 & 0.897 & 0.665 & 0.9 & 0.993 \\
\hline $\begin{array}{l}\text { Rao's } \\
\text { Spacing } \\
\text { (U) }\end{array}$ & 198.208 & 203 & 191.123 & 246.954 & 308.541 & 243.248 & 264.029 & 216.012 & 260.246 & 292 \\
\hline $\begin{array}{l}\text { Rao's } \\
\text { Spacing (p) }\end{array}$ & $<0.01$ & $<0.01$ & $<0.01$ & $<0.01$ & $<0.01$ & $<0.01$ & $<0.01$ & $<0.01$ & $<0.01$ & $<0.01$ \\
\hline $\begin{array}{l}\text { Dentary } \\
\text { Teeth }\end{array}$ & LD4* & LD6 & LD7* & LD13 & RD8 & RD9* & RD10* & RD12 & RD14* & \\
\hline $\mathbf{N}$ & 30 & 129 & 67 & 175 & 61 & 59 & 58 & 76 & 31 & \\
\hline $\operatorname{Mean} \theta^{\circ}$ & 53.65 & 54.44 & 55.09 & 43.44 & 53.82 & 51.29 & 52.96 & 43.61 & 40.78 & \\
\hline $\begin{array}{l}\text { Length of } \\
\theta^{\circ}(r)\end{array}$ & 0.905 & 0.884 & 0.886 & 0.548 & 0.85 & 0.976 & 0.987 & 0.9 & 0.958 & \\
\hline $\begin{array}{l}\text { Rao's } \\
\text { Spacing } \\
\text { (U) }\end{array}$ & 256 & 259.712 & 252.642 & 213.686 & 288.39 & 301.197 & 311.779 & 267.116 & 280.574 & \\
\hline $\begin{array}{l}\text { Rao's } \\
\text { Spacing (p) }\end{array}$ & $<0.01$ & $<0.01$ & $<0.01$ & $<0.01$ & $<0.01$ & $<0.01$ & $<0.01$ & $<0.01$ & $<0.01$ & \\
\hline
\end{tabular}

* Data for additional teeth not figured in text 
624 Figures with Legends

Frequency Histogram of Orientations Pooled from All Teeth in CMN 8889

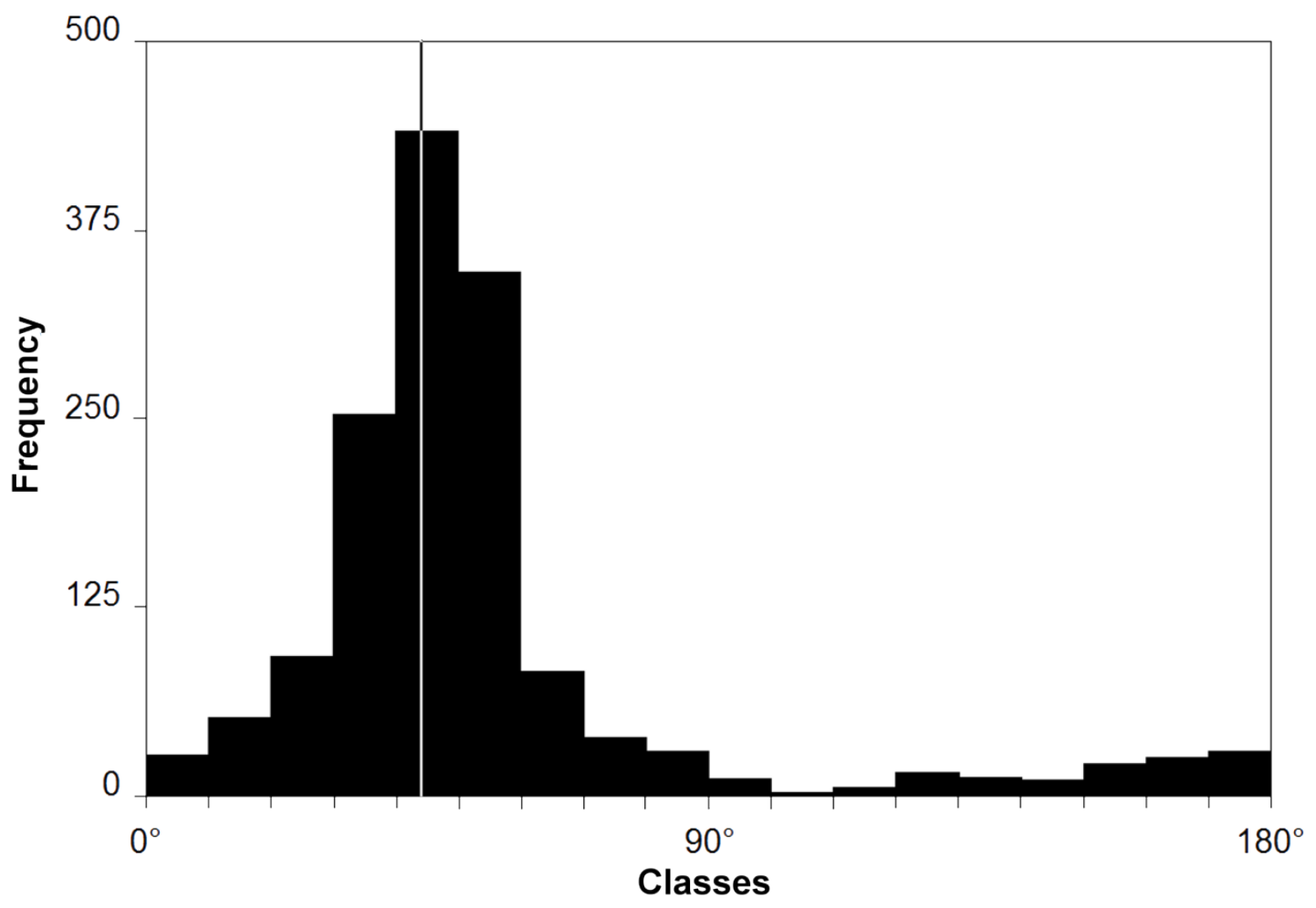

625

626 Figure 1: Histogram of striation orientations pooled from all teeth examined in

627 Leptoceratops gracilis (CMN 8889). Classes are in $10^{\circ}$ increments. A single mode is present, 628 with the greatest frequency of scratches in an arc from $30^{\circ}-60^{\circ}$. Line intersecting largest bar is

629 the pooled sample mean angle $\left(44 \cdot 1^{\circ}\right) . \mathrm{N}=1,504$. 

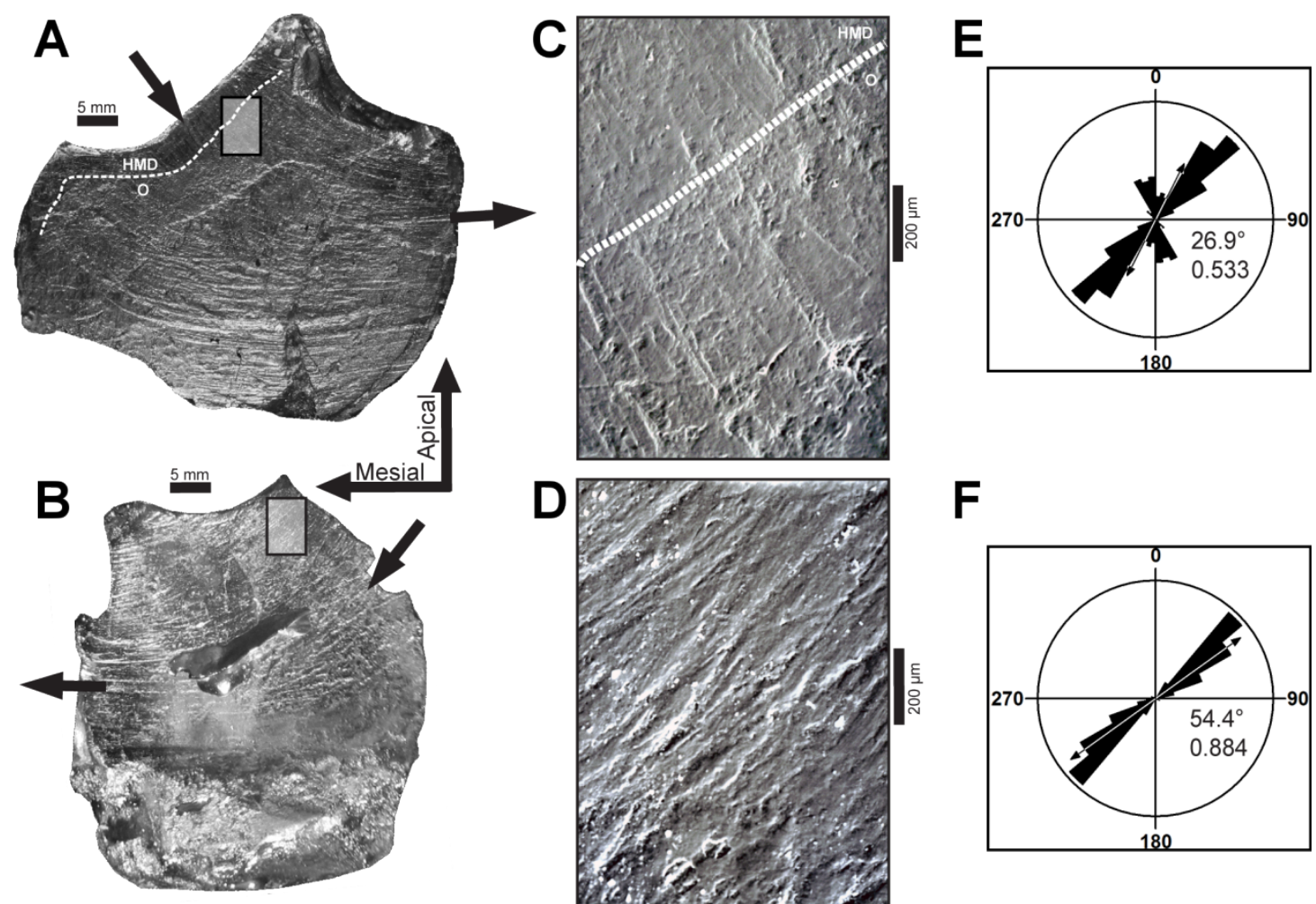
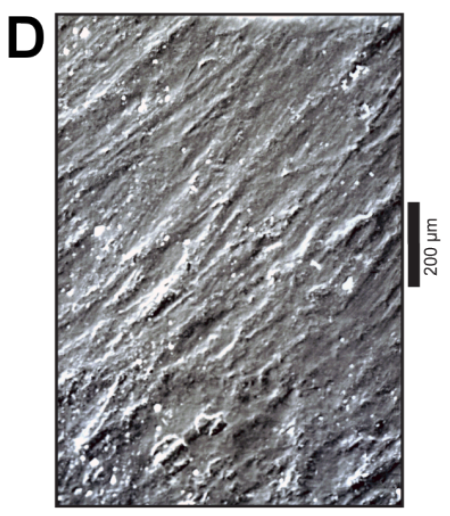

$\mathbf{F}$

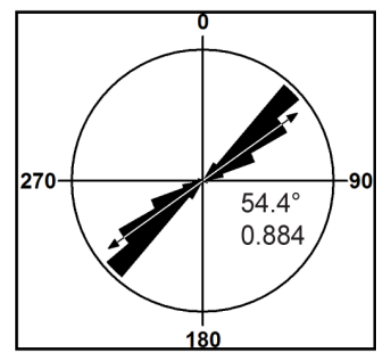

631 Figure 2: Dental microwear on representative teeth of Leptoceratops gracilis (CMN 8889).

632 (A) Light microscope images of the seventh left maxillary, and $(B)$ sixth left dentary teeth

633 showing curvilinear microwear traversing the entire occlusal surface. Arrows indicate the

634 direction of initiation and exit of the power stroke. Microwear near the site of initiation is

635 oriented caudodorsally whereas the same wear near the end of the stroke is oriented

636 rostrocaudally, a $\approx 50^{\circ}$ shift in orientation. Dotted lines in $A$ and $C$ demarcate approximate

637 junction of hard mantle dentine (HMD) with orthodentine (O). $(C, D)$ SEM micrographs imaged

638 from rectangles indicated in $A$ and $B$ respectively. At this magnification (100x) wear appears

639 uniform with a striation dominated texture. $(E, F)$ Rose diagrams of angular data from striations

640 in $C$ and $D$. Rose diagrams are on a unit circle and summarize angular orientation relative to

641 wear on a left dentary tooth. $90^{\circ}=$ caudal and $180^{\circ}=$ ventral directions. Values in lower right 
642 quadrant of rose diagrams are the mean angle and the length of the mean vector (r). Arrows in 643 rose diagrams indicates direction and magnitude of $\boldsymbol{r}$. 

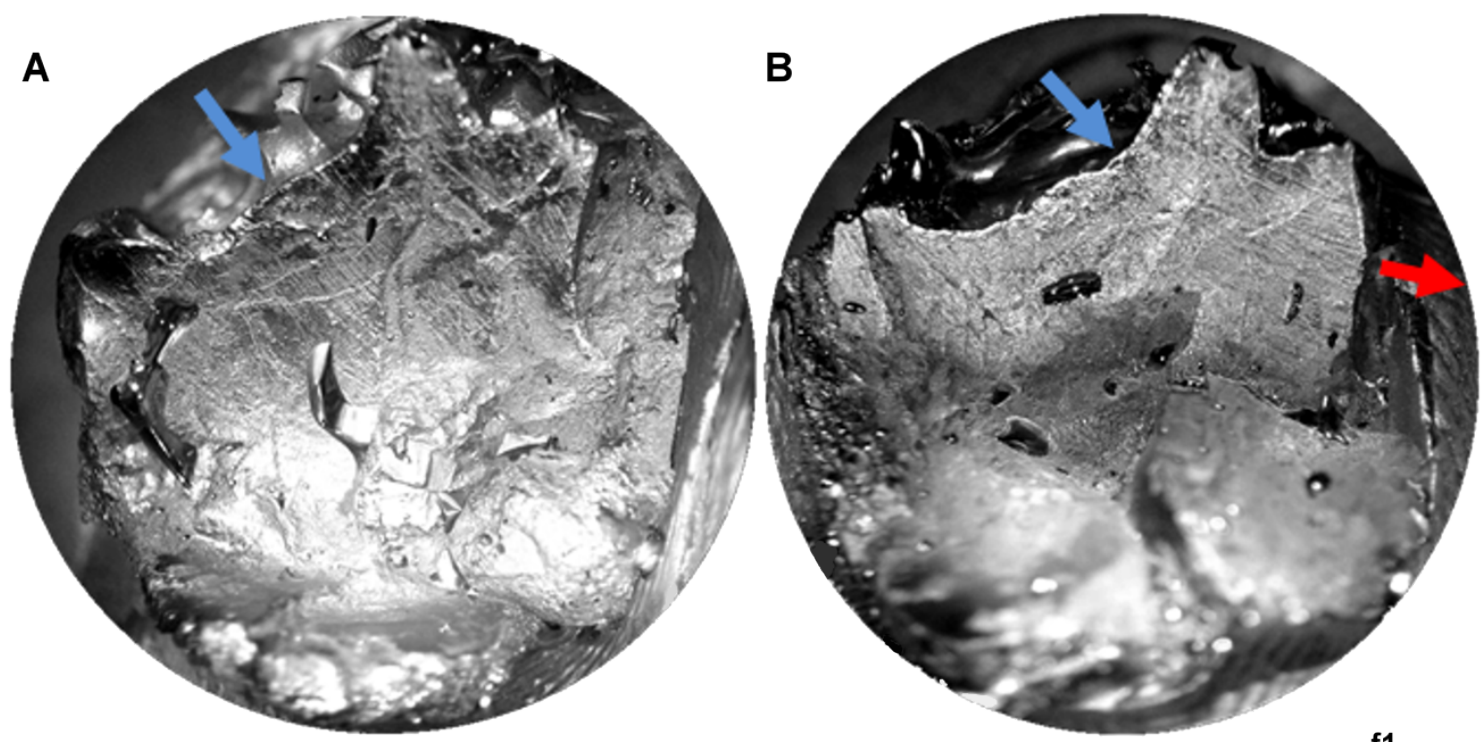

C
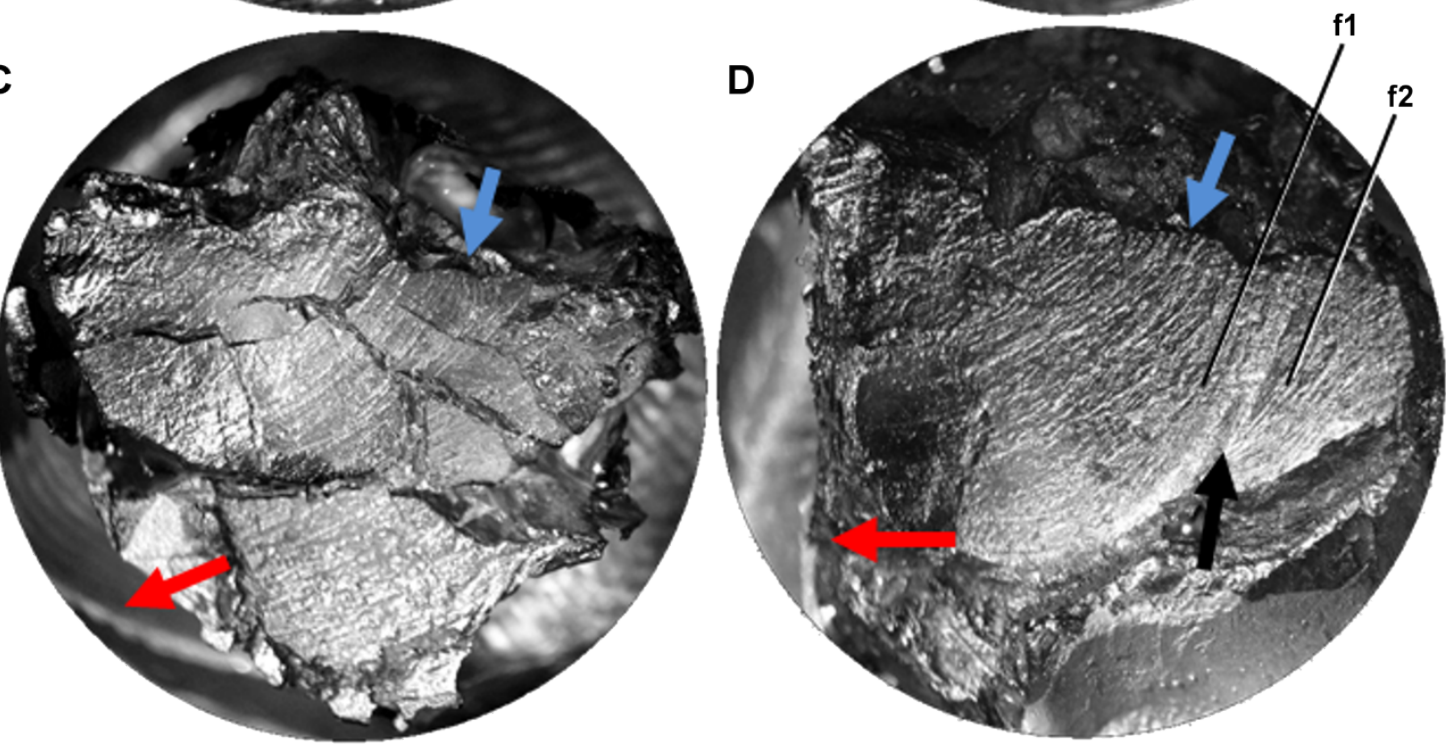

645

646 Figure 3: Light microscope images of additional teeth from Leptoceratops gracilis (CMN

647 8889) showing semicircular dental microwear. $(A)$ Eighth right dentary tooth. $(B)$ 12th right

648 dentary tooth. $(C)$ 10th right maxillary tooth. $(D)$ 11th right maxillary tooth. Colored arrows

649 correspond to those in Fig. 6 and indicate (where visible) the overall orientation of microwear at

650 the initiation (blue) and ending (red) of the power stroke. Arrow (black) in $D$ indicates step

651 between two facets $(\mathrm{f} 1, \mathrm{f} 2)$ formed via differential wear. These facets were likely caused by the 
652 occlusion of this tooth against two opposing right dentary teeth at different stages of eruption.

653 Images not to scale. 
A

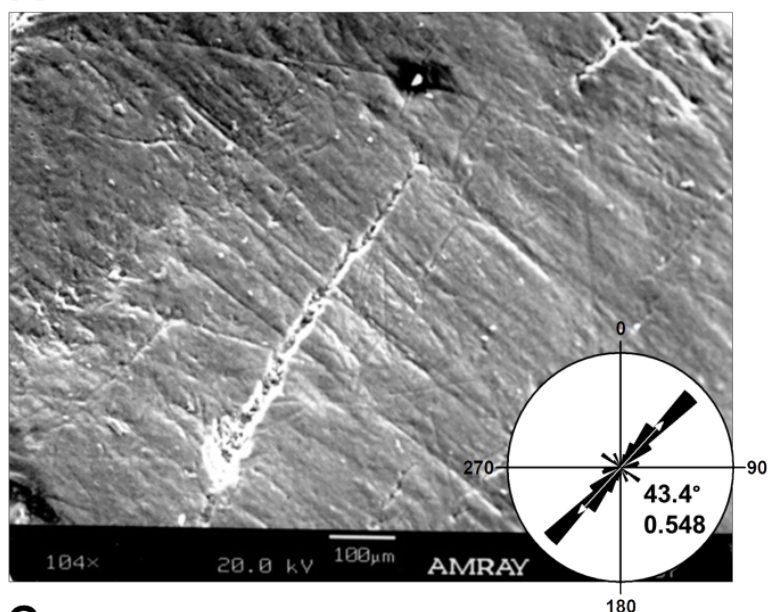

C

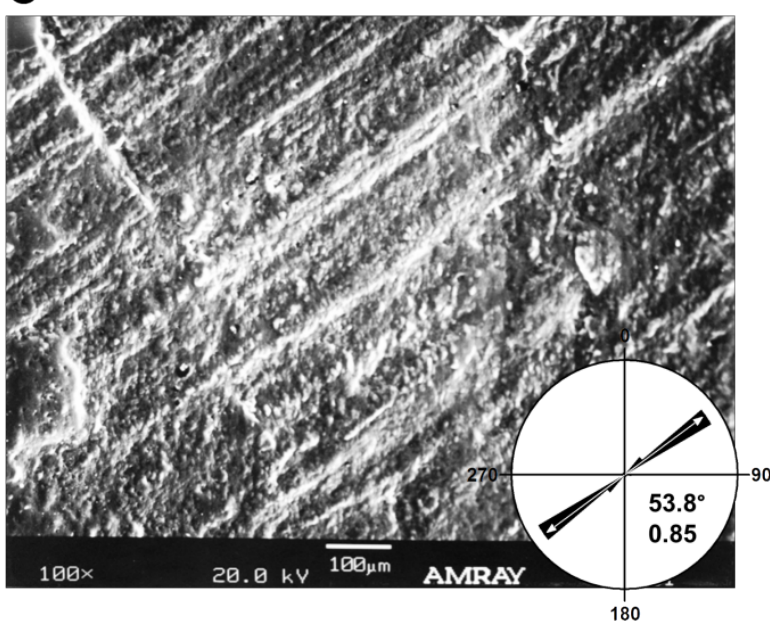

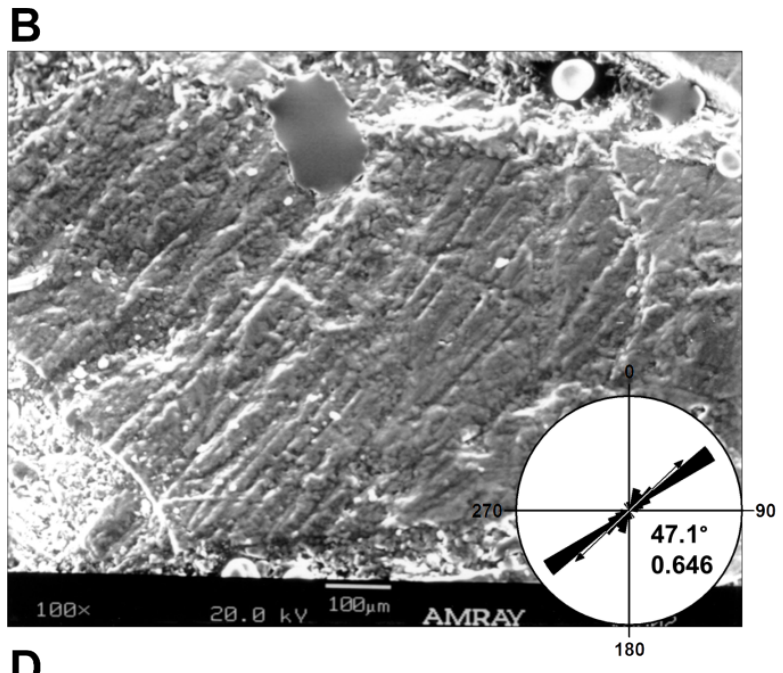

D

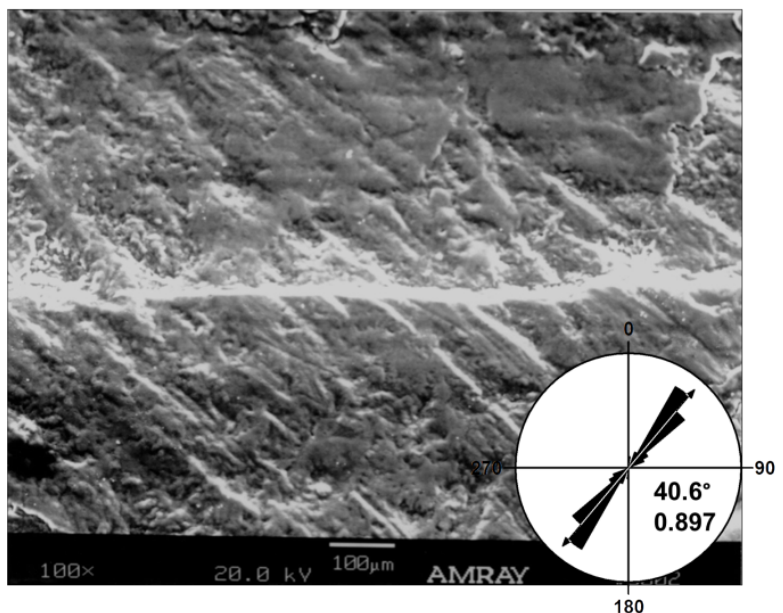

655 Figure 4: Micrographs of selected teeth from each of the four dental quadrants in

656 Leptoceratops gracilis (CMN 8889). $(A) 13^{\text {th }}$ left dentary tooth, $(B)$ sixth left maxillary tooth,

657 (C) eighth right dentary tooth, and $(D)$ fourth right maxillary tooth. Orientations of micrographs

658 are as follows; apical at left and basal at right. In left dentary and left maxillary micrographs

659 distal is at top and mesial is at bottom. In right dentary and right maxillary images distal at

660 bottom and mesial is at top. Rose diagrams summarize angular orientation relative to wear on a

661 left dentary tooth. Description of rose diagram orientation and data are the same as in Fig. 2. 

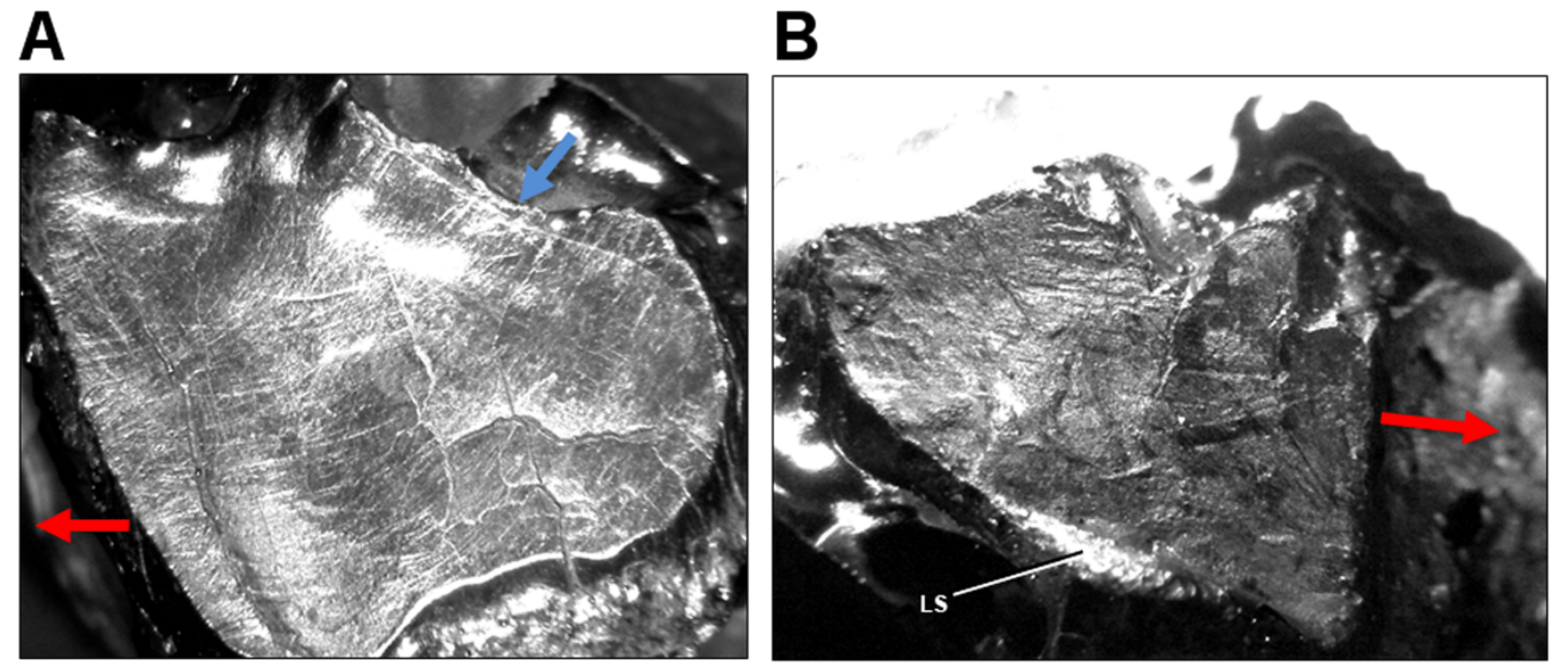

663 Figure 5: Light microscope images of dental microwear in additional specimens of

664 Leptoceratops. (A) Isolated right maxillary tooth assigned to Leptoceratops (YPM VPPU

665 018133) showing semicircular dental microwear. (B) Fifth right dentary tooth from

666 Leptoceratops gracilis (AMNH FR 5205) showing a predominance of mesiodistally oriented

667 wear near the base of the facet, and in a similar orientation as the labial shelf (LS). Colored

668 arrows correspond to those in Fig. 6 and indicate the overall orientation of microwear at the

669 initiation (blue) and ending (red) of the power stroke. Images not to scale. 


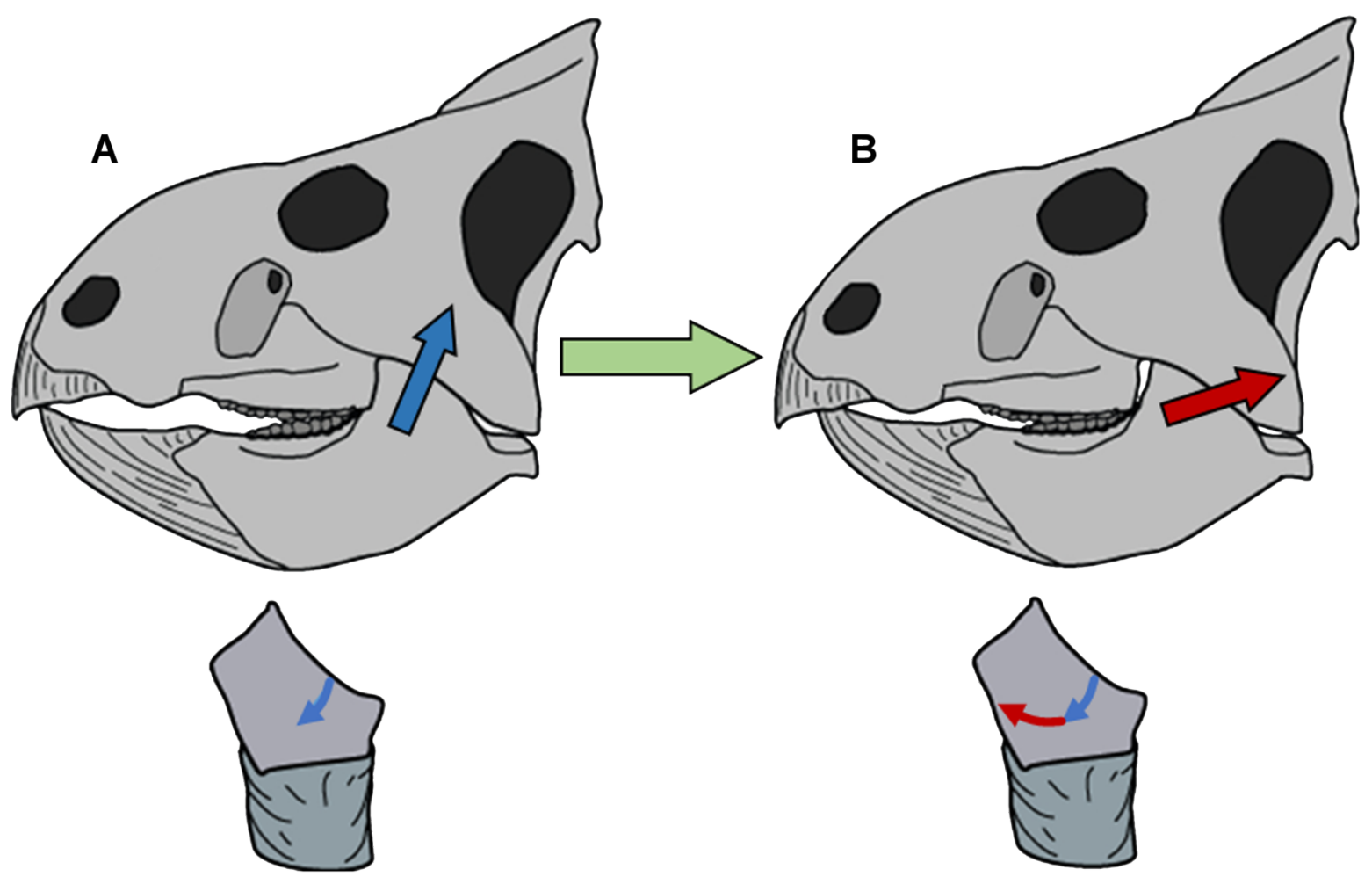

670

671

672 Figure 6: Model of circumpalinal mastication in Leptoceratops. (A) Adduction of the lower

673 jaw dominated by action (blue arrow) of the $m$. adductor mandibulae externus group (mAME)

674 and beginning of the power stroke of mastication. $(B)$ Progression of the power stroke into a

675 palinal (retraction) phase dominated by transition from the mAME to action (red arrow) of the $m$.

676 addcutor mandibulae posterior (mAMP). Below each skull is a left dentary tooth with colored

677 arrows demarcating the segment and direction of microwear striations that result from the

678 aforementioned muscular actions. 